\title{
Chapter 12 \\ Proposal for a Global Renewable Energy \\ Production and Storage Initiative
}

A review of the vast literature on the danger posed by climate change shows an amazing absence of the global engineering community in proposing specific approaches to implement substantial global carbon dioxide reductions by a specified deadline. The Saturn-Apollo project is often cited as an example to be adopted for the formulation of a Global Apollo Project for renewable energy production. Unfortunately, the Global Apollo Program proposed by King et al. [1] lacks the specificity to convince the politicians and the general public that solutions are possible.

We therefore suggest that there is an urgent need for the establishment of a Global Engineering Council for the purpose of soliciting proposals and conducting a comparative evaluation of these engineering proposals to achieve the goal of global renewable global power production and storage no later than by mid-century [2]. This Council should also develop criteria for the purpose of ranking the various proposals as to their technical, economic, and socio-political feasibility. Furthermore, it should summarize the methodology used for their rankings in generally understandable terms and disseminate the results of its deliberations to various governmental entities and to the general public through various media outlets. Our own views on the available engineering options are given in reference [3].

\section{References}

1. D. King, J. Browne, R. Layard, G. O'Donnell, M. Rees, N. Stern, A. Turner, A Global Apollo Programme to Combat Climate Change. Center for Economic Performance, The London School of Economics and Political Science, 2015

2. M.F. Platzer, On the need for a global engineering initiative to mitigate climate change. Int. J. Energy Prod. Manag. 1(2), 155-162 (2016)

3. M.F. Platzer, N. Sarigul-Klijn, Engineering Options for an Emission-Free Global Economy by 2050. Proceedings of the ASME 2016 International Mechanical Engineering Congress and Exposition IMECE2016-66345, November 11-17, 2016, Phoenix, Arizona

(C) The Editor(s) (if applicable) and The Author(s), under exclusive license to 